DOI: 10.12731/2658-4034-2021-12-5-37-51

УДК 372.881.1

\title{
ВИДЕОКОНФЕРЕНЦИЯ \\ КАК ТЕХНОЛОГИЯ ДИСТАНЦИОННОГО \\ ОБУЧЕНИЯ ГОВОРЕНИЮ НА ИНОСТРАННОМ ЯЗЫКЕ \\ В СТАРШЕЙ ШКОЛЕ В ПЕРИОД ПАНДЕМИИ: \\ ОПЫТ ФИНЛЯНДИИ И РОССИИ
}

\section{П.А. Лехницкая}

Цель. Статья посвящена разработке методических рекомендачий по применению видеоконференций в обучении говорению на иностранном языке на основе сравнительно-сопоставительного анализа использования данной технологии в финской и российской старшей школе в рамках пандемии.

Метод или методология работы. За основу исследования взяты статьи, видеоматериаль, блоги учителей иностранного языка, посвященные дистанционному образованию в период пандемии COVID-19 Финляндии и России.

В работе использованы описательный метод, метод сравнительного анализа.

Результаты. В ходе исследования был проанализирован опыт использования видеоконференций в организации дистанциионного урока иностранного языка, направленного на развитие навыков говорения, в старшей школе Финляндии и России, на основе чего были разработаны методические рекомендации.

Область применения результатов. Результаты исследования могут быть использованы в организачии дистанционного урока иностранного языка, направленного на обучение говорению в старшей школе.

Ключевые слова: видеоконференция; говорение; дистанционное обучение; иностранный язык; сравнительно-сопоставительный анализ 


\section{VIDEOCONFERENCE AS A TECHNOLOGY OF DISTANCE LEARNING FOR SPEAKING A FOREIGN LANGUAGE IN HIGH SCHOOL DURING A PANDEMIC: THE EXPERIENCE OF FINLAND AND RUSSIA}

\section{P.A. Lekhnitskaya}

Purpose. The article is devoted to the development of guidelines for the use of videoconference in teaching speaking a foreign language based on a comparative analysis of the use of this technology in Finnish and Russian high schools in the framework of the pandemic.

Methodology. The research is based on articles, videos, blogs of foreign language teachers dedicated to distance education during the COVID-19 pandemic in Finland and Russia. The work uses a descriptive method, a method of comparative analysis.

Results. In the course of the study, the experience of using videoconferences in organizing a distance lesson of a foreign language aimed at developing speaking skills in high schools in Finland and Russia was analyzed, on the basis of which methodological recommendations were developed.

Practical implications. The research results can be used in the organization of a distance foreign language lesson aimed at teaching speaking in high school.

Keywords: videoconference; speaking; distance learning; foreign language; comparative analysis

\section{Введение}

Пандемия COVID-19 ускорила процесс внедрения информационных технологий в современную школу. Если раньше вопрос использования технологии видеоконференций в обучении говорению на иностранном языке имел дискуссионный характер, то недавно образовательные учреждения были вынуждены использовать данные технологии на практике.

К моменту закрытия школ и их перевода на дистанционный формат обучения уже был накоплен определенный опыт использования 
видеосвязи на уроке иностранного языка. Биргулиева Д.А. и Подляцкая А.В. описывают урок, где с использованием видеоконференций учащиеся совместно с педагогом общаются с носителем изучаемого языка. Подобное общение имеет положительное влияние на развитие навыков говорения и аудирования, устраняет фонетические ошибки. Педагоги и психологи указывают на меньшую утомляемость коллектива, повышение мотивации. Авторы отмечают, что видеоконференцсвязь способствует преодолению языкового барьера, готовит учащихся к межкультурному диалогу [4]. Однако подобные уроки не предполагает полного перехода на дистанционный формат обучения, а служит лишь вспомогательным средством в обучении говорению на иностранном языке в массовой школе. Научная новизна исследования заключается в том, что во время перевода школ на дистанционный формат обучения учителя были вынуждены проводить уроки только в дистанционном формате, посещение школ в целях предотвращения распространения новой коронавирусной инфекции было ограничено, из-за чего были выявлены сильные и слабые стороны ведения уроков, направленных на развитие навыков говорения, в рамках видеоконференций.

Актуальность исследуемой проблемы обусловлена тем, что был получен ценный опыт ведения уроков иностранного языка дистанционно, который не получил достаточного рассмотрения. Сравнительно-сопоставительный анализ способов использования видеоконференций в обучении говорению в Финляндии и России в период дистанционной работы школ во время пандемии позволит выявить основные трудности, с которыми столкнулись учителя обеих стран и выделить основные преимущества данной технологии.

\section{Результаты исследования и их обсуждения}

Резкая смена формата обучения предполагает пересмотр существующих технологий обучения иностранному языку. Е.В. Шарохина, О.О. Петрова, О.В. Долганова под технологией обучения понимают совокупность средств и методов воспроизведения теоретически обоснованных процессов обучения и воспитания, позволяющих успеш- 
но реализовывать поставленные образовательные цели [11]. Одной из выбранных технологий для обучения в дистанционном формате в данный период стали видеоконференции. Гладков А.В. кандидат педагогических наук, доцент, Тюменского высшего военно-инженерного командного училища им. Маршала инженерных войск А.И. Прошлякова под видеоконференцией понимает технологию, которая дает возможность всем субъектам образовательного процесса видеть и слышать друг друга, настроить между собой обмен информацией и совместно обрабатывать ее в интерактивном режиме, пользуясь возможностями компьютера, что максимально приближает общение на расстоянии к реальному живому общению [6]. Особенность урока иностранного языка заключается в том, что ведущим компонентом содержания обучения являются способы деятельности, т.е. учитель ставит перед собой цель обучить видам речевой деятельности, сформировать коммуникативную компетенцию. Благодаря возможности видеоконференций приближать онлайн общение к живому, данная технология отвечает требованиям организации урока иностранного языка.

В финской школе во время использования видеоконференций при обучении говорению дистанционно в период пандемии методы обучения остались прежними: проводились дискуссионные задания в парах и группах, презентации, ролевые игры, упражнения на произношение, ученики читали вслух [22]. В своем исследовании Senni Rekola и Mona Siltanen провели интервью с финскими учителями. Учителя поделились, какими способами организовывали процесс обучения говорению на старшем этапе обучения. Так, Anja, Hilla и Annika перед уроком представляли ученикам план предстоящей работы. Другие учителя применяли групповые формы работы, для выполнения которых создавались отдельные встречи:

Maria: «Я использовала упражнения на развитие навыков говорения, например, групповые дискуссионные упражнения, которые при контактном обучении ученики выполняют со своими друзьями. Для этой цели они создают собственное собрание в Google Meets»

Hilla: «Я поощряла совместную работу учеников и проводила опросы $<\ldots>$. Если в книге было упражнение на развитие навы- 
ков говорения, я не принуждала учеников работать с определенной группой, разрешая им делать выбор самостоятельно <... . Я старалась найти подход к каждому ученику»

Annika: «Я разделяла студентов на группы, каждая группа создавала собственный канал в программе <..>. В конце у нас была общая встреча, где я подводила итоги урока и отправляла домашнее задание в чат группы» [22].

Практически все респонденты отметили, что в своей работе они создавали отдельные каналы или же собрания для группового выполнения задания, направленного на развитие навыков говорения, индивидуализируя процесс обучения. В общей встрече сложно организовать данную работу - группы учеников не могут одновременно проводить обсуждение задания в одном канале. Для этой цели финские учителя создают дополнительные каналы для коммуникации в рамках отдельной группы.

В российской школе, во время проведения видеоконференции, для понимания степени усвоения лексического материала учителя использовали устный опрос, имели возможность давать обратную связь как мгновенно, так и отложено - с использованием трансляции экрана или чата $[3,15]$. Данные средства реализации обратной связи сильно отличаются от привычных: во время очного обучения учитель напрямую сообщает ученику о качестве его устного ответа, в рамках видеоконференций необходимо прибегать к интерактивным средствам.

Учитель английского языка ГБОУ №388, Кировского района Андреева Анастасия Андреевна отмечает, что «обучение иностранному языку подразумевает коммуникативные задания; использование парных, групповых форм работы. С реализацией данных форм работ возникли трудности, но использование инновационных технологий облегчило ситуацию. Использование инновационных технологий позволяет реализовать метод проектов в рамках школьного дистанционного обучения посредством социальных сетей и платформы для организации видеоконференций “Zoom”» [2].

На канале МБОУ СОШ №2 п. Пурпе, размещенном на видеохостинге "YouTube", в видеоматериале представлен дистанционный 
урок английского языка в 10 классе, в котором обучение говорению проходило в рамках видеоконференции с использованием упражнений на перевод. Стоит отметить, что практически не был задействован потенциал платформы «Zoom», которая предлагает различные средства интерактивного ведения видеоконференции, что свидетельствует о недостаточном понимании интерактивных инструментов данной платформы [13].

Особенностью обучения говорению в рамках видеоконференций являются особые требования к ученику. Так, учитель английского языка МБОУ «Рыльская средняя общеобразовательная школа №4» г. Рыльск Е.А. Макоивец отмечает, что во время дистанционных уроков в программе «Skype» был обозначен алгоритм ответов, где ученики показывали готовность к ответу при помощи определенного знака - таким образом ученики не перебивали друг друга и занятие не превращалось в «слабо контролируемый полилог». Данная функция программы представляет особую важность в обучении говорению, так как когда говорят несколько учеников одновременно, их голоса перебиваются и трудно отслеживать правильность речи. В плане урока Е.А. Макоивец не отмечает заметных изменений при переходе на дистанционный формат обучения, он состоит из: «вступительной части, проверки домашнего задания, введения материала, его отработки и закрепления, выставления оценок и отметок, задания на дом с визуальным и голосовым пояснением». В данном случае удобны электронные формы составляющих УМК, так как учитель может включить трансляцию экрана и поделиться содержимым с учащимися [9].

В данных странах по-разному проходила организация учебной недели и уроков иностранного языка. Так, в финской средней школе Сипоо (Sipoo High School), расположенной на окраине города Хельсинки, учебная программа, структура урока и экзаменационная неделя не изменились. Все запланированные занятия проходили в дистанционной форме, каждый урок длился 75 минут. Директор и учителя разработали принципы ведения уроков, среди которых было проведение занятий онлайн, обязательное присутствие учителя, всех учеников [17]. В России в МАОУ «Гимназия г.Сосногорска», напротив, по данным Бор- 
щик Д.В., Борщик Л.Н. и Чиркововой Л.Н., с учетом САНПин продолжительность дистанционного урока для учащихся старшей школы не превышала 30 минут. Один раз в неделю проводился урок английского языка, на котором были использованы видеоконференции. На данном уроке закреплялся пройденный материал, оценивалась корректность произношения звуков, проводились дискуссии [5].

Для обучения говорению на иностранном языке в рамках видеоконференций в России широко использовались платформы «Zoom», «Skype», «Microsoft Teams» [1], в Финляндии - «Teams» [2], Google платформы, сервисы Office 365, «Zoom». «Whatsapp» [21].

Важным фактором являются преимущества, выявленные во время использования видеоконференций в обучении говорению на иностранном языке. Так, финскими учеными среди них были выделены: легкость в участии в онлайн обсуждениях, возможность учиться в тихом месте без отвлекающих факторов, что способствует лучшей концентрации, отсутствие буллинга $[17,19]$. В России обратили внимание на возможность записи и просмотра урока $[3,7]$.

Однако использование данной технологии дистанционного обучения на уроках иностранного языка вызывало немало трудностей в обеих странах. Среди них отсутствие живого общения с преподавателем, возможности воспринимать речь вживую, стеснение говорить и переспрашивать, во время нахождения за экраном, почти не практиковалась устная речь [12]. Кроме того, была некоторая изоляция, в то время как язык предполагает социальное взаимодействие, существовала проблема с мотивацией школьников $[17,20]$. В России серьезной проблемой стало отсутствие отечественной платформы для организации видеоконференций, из-за чего возникала угроза конфиденциальности данных [8], в Финляндии Финское Национальное Агентство Образования помогало школам в организации дистанционного обучения [17], Хельсинский университет разработал специальную инструкцию, в которой подробно рассказывается особенности использования платформы «Zoom», информационную безопасность [22].

Другой проблемой в России стало техническое оснащение школ и наличие технических средств у учеников, без решения этой проблемы 
становится невозможной организация дистанционного обучения говорению. Если в Финляндии ноутбуки и планшеты выдавались школой, и проблемным оставалось только качество интернет-соединения [16], в России их не выдавали, во многих населенных пунктах интернета практически не было [12]. Согласно информации, предоставленной новостным агентством «Комсомольская Правда», в Общественной палате и институте прогрессивного образования было принято решение о выдаче компьютеров и роутеров на период дистанционного обучения [10], однако неизвестно, насколько данное решение будет реализовано. Данное исследование обусловлено коротким промежутком времени, в течение которого применялись видеоконференции в дистанционном обучении говорению на уроках иностранного языка. В связи с этим в последующих исследованиях необходимо в долгосрочной перспективе рассмотреть влияние данного средства дистанционного обучения на развитие навыков говорения учеников старших классов, так как использование видеоконференций обладает преимуществами, которые представляют особую ценность в образовательном процессе.

\section{Вывод}

Сравнительно-сопоставительный анализ использования видеоконференций в старших классах российских и финских школ показал, что в процессе дистанционного обучения говорению в обеих странах возникали технические трудности, связанные с интернет-соединением и наличием ноутбуков, планшетов у учащихся. Технические проблемы решаются пересмотром плана финансирования учебных заведений, для решения методических проблем необходимо обратиться к опыту организации дистанционного обучения говорению в школах данных стран. Отметим, что в рамках использования технологии видеоконференций методы обучения остались прежними, изменились средства, в качестве которых выступили интерактивные платформы, программы для проведения видеоконференций. Данные средства предполагают использование интерактивных функций, ресурсов для организации урока иностранного языка, без использования которых полностью не реализовывается потенциал технологии видеоконференций в обучении говорению на иностранном языке. 
Опираясь на опыт использования технологии видеоконференций в обучении говорению на иностранном языке в старших классах, учителю для ведения урока в рамках видеоконференции необходимо:

1. Создавать отдельные собрания (каналы) для выполнения дискуссионных речевых упражнений в группах;

2. Активно использовать речевые упражнения, презентации, метод проектов, проводить ролевые игры, чтение вслух, проводить устный опрос для закрепления лексики;

3. Ознакомиться с инструментами, которые предлагает платформа, для организации устных высказываний учеников;

4. Из-за изменения формата вербальных средств обучения необходимо помнить, что возможность оценки точность речевого высказывания ученика реализуется через интерактивные средства, которые предлагает видеоконференция

5. Для выполнения речевых заданий по УМК более эффективно использовать электронные версии печатных изданий через трансляцию экрана учителя

В качестве платформы для проведения видеоконференций можно использовать «Zoom», «Skype», «Microsoft Teams», Google платформы, сервисы Office 365, «Whatsapp». Данные платформы активно использовались финскими и российскими учителями в период пандемии COVID-19 в обучении говорению. Они представляют широкий спектр возможностей для организации дистанционного урока иностранного языка.

Продолжительность урока, направленного на развитие навыков говорения, в рамках видеоконференций и частота использования видеоконференций зависит от местного законодательства. Так, в России с учетом САНПин дистанционный урок в старшей школе длился 30 минут, когда в Финляндии, где система образования децентрализована и школы по большей части автономны, продолжительность урока составила 75 минут.

Интеграция данного опыта позволит добиться максимальной продуктивности использования видеоконференций во время дистанционного урока иностранного языка, направленного на обучение говорению. 


\section{Список литературы}

1. Абдыльманова Р.Х. Омарова Х.С. Эффективность дистанционного обучения иностранному языку в период пандемии // Электронный научно-методический журнал Омского ГАУ. 2020. № 3 (22). https://e-journal. omgau.ru/images/issues/2020/3/00860_1.pdf(дата обращения: 20.10.2021).

2. Андреева А.А. Урок английского языка в условиях пандемии Covid-19, 2020. https://infourok.ru/urok-anglijskogo-yazyka-v-usloviyah-pandemiicovid-19-4625888.html (дата обращения: 20.10.2021).

3. Белоусова М.М. О некоторых особенностях взаимосвязанного развития речевых навыков на иностранном языке при обучении онлайн // Инженерный вестник Дона. 2020. №11. http://www.ivdon.ru/ uploads/article/pdf/IVD_29_11_belousova.pdf_06c8593e53.pdf(дата обращения: 20.10.2021).

4. Биргулиева Д.А., Подляцкая А.В. Проведение урока иностранного языка на основе использования информационных технологий применение видеоконференций на уроках английского языка. http:// scipro.ru/files/2016/12/education_12_2016.pdf\#page=127 (дата обращения: 20.10.2021).

5. Борщик Д.В. Особенности организации дистанционного обучения иностранному языку в школе в условиях пандемии / Д.В. Борщик, Л.Н. Борщик, Л.Н. Чиркова // Дистанционные образовательные технологии: сборник трудов V Международной научно-практической конференции, Ялта, 22-25 сентября 2020 года / Ответственный редактор В.Н. Таран. Симферополь: ООО «Издательство Типография «Ариал», 2020. С. 33-35.

6. Гладков А.В. Интерактивные технологии обучения в организации самостоятельной работы студентов / А.В. Гладков, Л.И. Кутепова, А.В. Трутанова // Успехи современной науки. 2017. Т. 1, № 3. С. 53-55.

7. Евдошенко О. В. Традиционное и дистанционное обучение в условиях пандемии 2020 года // Наука и Образование. http://www.opusmgau. ru/index.php/see/article/view/1626 (дата обращения: 20.10.2021)

8. Кинякина Е. Сервис конференц-связи Zoom оказался скомпрометирован // Ведомости. 04.04.2020. https:/www.vedomosti.ru/technology/ articles/2020/04/04/827177-zoom (дата обращения: 20.10.2021) 
9. Макоивец Е.А. Из опыта работы: использование программы Skype при дистанционном обучении английскому языку // Актуальные проблемы современного иноязычного образования. 2020. № 11. C. 12 .

10. Нуждающимся школьникам предложили выдавать компьютеры и роутеры на период дистанционного обучения, 2020. https:/www. kp.ru/online/news/3807823/ (дата обращения: 20.10.2021)

11. Петрова О., Долганова О., Шарохина Е. Педагогика. Конспект лекций. https://www.gumer.info/bibliotek_Buks/Pedagog/konspekt/index. php (дата обращения: 20.10.2021)

12. Проблемы перехода на дистанционное обучение в Российской Федерации глазами учителей / Д.И. Сапрыкина, А.А. Волохович; Национальный исследовательский университет «Высшая школа экономики», Институт образования. М.: НИУ ВШЭ, 2020. 32 с. (Факты образования № 4 (29)). https://ioe.hse.ru/mirror/pubs/share/368265542.pdf

13. Урок английского языка в 10 классе «zoom», 2020. https://www.youtube. com/watch?v=WHCqtfdwblw\&t=673s (дата обращения: 20.10.2021)

14. Федунова М.Н. Проблемы дистанционного обучения иностранным языкам в условиях пандемии // Символ науки. 2021. №3. С. 119-123.

15. Andrews R. Does e-Learning Require a New Theory of Learning? Some Initial Thoughts // Journal for Educational Research Online. 2011. Vol. 3, No 1. P. 104-121.

16. As finnish teachers move classes online, family routines change, 2020. https://finland.fi/life-society/as-finnish-teachers-move-classes-onlinefamily-routines-change/ (дата обращения: 20.10.2021)

17. Niemi H.M., Kousa P. A case study of students' and teachers' perceptions in a Finnish high school during the COVID pandemic // International Journal of Technology in Education and Science (IJTES), 2020. Vol. 4, no. 4. P. 352-369. https://doi.org/10.46328/ijtes.v4i4.167

18. How countries are using edtech (including online learning, radio, television, texting) to support access to remote learning during the COVID-19 pandemic. https://www.worldbank.org/en/topic/edutech/brief/ how-countries-are-using-edtech-to-support-remote-learning-during-thecovid-19-pandemic (дата обращения: 20.10.2021) 
19. Loima J. Socio-Educational Policies and Covid-19 - A Case Study on Finland and Sweden in the Spring 2020 // International Journal of Education and Literacy Studies. 2020. Vol. 8, No 3. P. 59-75. http:// dx.doi.org/10.7575/aiac.ijels.v.8n.3p.59

20. Taipale P. Finnish Primary Teacher's Experiences of Remote Teaching during COVID-19 School Closures // Master's Thesis, 62 p. January 2021. https://www.utupub.fi/bitstream/handle/10024/151160/PaulaTaipale. pdf?sequence=1\&isAllowed=y (дата обращения: 20.10.2021)

21. Aarnos R. Teaching and supporting students with special-educational needs at distance during the COVID-19 school closures in Finland: Special needs teachers' experiences // Thesis for Master's degree. https://www.doria.fi/bitstream/handle/10024/180693/aarnos_riikka. pdf?sequence=4\&isAllowed=y (дата обращения: 20.10.2021

22. Senni Rekola, Mona Siltanen. Finnish EFL teachers' experiences during the emergency remote teaching period in spring 2020 // Master's Thesis, https://jyx.jyu.fi/bitstream/handle/123456789/74516/URN\%3aNBN\%3af i\%3ajyu-202103081873.pdf?sequence=1\&isAllowed=y (дата обращения: 20.10.2021).

23.ZOOM. https://helpdesk.it.helsinki.fi/en/instructions/collaboration-andpublication/video-conferencing/zoom (дата обращения: 20.10.2021)

\section{References}

1. Abdyl'manova R.Kh. Omarova Kh.S. Effektivnost' distantsionnogo obucheniya inostrannomu yazyku v period pandemii [The effectiveness of distance learning a foreign language during a pandemic]. Elektronny nauchno-metodicheskiy zhurnal Omskogo GAU, 2020, no. 3 (22). https://e-journal.omgau.ru/images/issues/2020/3/00860_1.pdf (accessed 20.10.2021).

2. Andreeva A.A. Urok angliyskogo yazyka v usloviyakh pandemii Covid-19 [English lesson in the context of the Covid-19 pandemic], 2020. https://infourok.ru/urok-anglijskogo-yazyka-v-usloviyah-pandemii-covid-19-4625888. html (accessed 20.10.2021).

3. Belousova M.M. O nekotorykh osobennostyakh vzaimosvyazannogo razvitiya rechevykh navykov na inostrannom yazyke pri obuchenii onlayn [On some features of the interrelated development of speech skills 
in a foreign language when teaching online]. Inzhenernyy vestnik Dona, 2020, no. 11. http://www.ivdon.ru/uploads/article/pdf/IVD_29_11_belousova.pdf_06c8593e53.pdf (accessed 20.10.2021).

4. Birgulieva D.A., Podlyatskaya A.V. Provedenie uroka inostrannogo yazyka na osnove ispol'zovaniya informatsionnykh tekhnologiy-primenenie videokonferentsiy na urokakh angliyskogo yazyka [Conducting a foreign language lesson based on the use of information technology - the use of video conferencing in English lessons]. http://scipro.ru/files/2016/12/ education_12_2016.pdf\#page=127 (accessed 20.10.2021).

5. Borshchik D.V., Borshchik L.N., Chirkova L.N. Osobennosti organizatsii distantsionnogo obucheniya inostrannomu yazyku v shkole $\mathrm{v}$ usloviyakh pandemii [Features of the organization of distance learning a foreign language at school in a pandemic]. Distantsionnye obrazovatel'nye tekhnologii: sbornik trudov V Mezhdunarodnoy nauchno-prakticheskoy konferentsii, Yalta, 22-25 sentyabrya 2020 goda [Distance educational technologies: collection of works of the V International scientific-practical conference, Yalta, September 22-25, 2020] / Ed. V.N. Taran. Simferopol': OOO «Izdatel'stvo Tipografiya «Arial», 2020. S. 33-35.

6. Gladkov A.V., Kutepova L.I., Trutanova A.V. Interaktivnye tekhnologii obucheniya v organizatsii samostoyatel'noy raboty studentov [Interactive learning technologies in organizing students' independent work]. Uspekhi sovremennoy nauki, 2017, vol. 1, no. 3, pp. 53-55.

7. Evdoshenko O.V. Traditsionnoe i distantsionnoe obuchenie v usloviyakh pandemii 2020 goda [Traditional and distance learning in the pandemic of 2020]. Nauka i Obrazovanie. http://www.opusmgau.ru/index.php/ see/article/view/1626 (accessed 20.10.2021)

8. Kinyakina E. Servis konferents-svyazi Zoom okazalsya skomprometirovan [The Zoom conference call service was compromised]. Vedomosti. 04.04.2020. https://www.vedomosti.ru/technology/articles/2020/04/04/827177-zoom (accessed 20.10.2021)

9. Makoivets E.A. Iz opyta raboty: ispol'zovanie programmy Skype pri distantsionnom obuchenii angliyskomu yazyku []. Aktual'nye problemy sovremennogo inoyazychnogo obrazovaniya [Actual problems of modern foreign language education], 2020, no. 11, p. 12. 
10.Nuzhdayushchimsya shkol'nikam predlozhili vydavat' komp'yutery $i$ routery na period distantsionnogo obucheniya [Schoolchildren in need were offered to issue computers and routers for the period of distance learning], 2020. https://www.kp.ru/online/news/3807823/ (accessed 20.10.2021).

11. Petrova O., Dolganova O., Sharokhina E. Pedagogika. Konspekt lektsiy [Pedagogy. Lecture notes]. https://www.gumer.info/bibliotek_Buks/ Pedagog/konspekt/index.php (accessed 20.10.2021)

12. Saprykina D.I., Volokhovich A.A. Problemy perekhoda na distantsionnoe obuchenie $v$ Rossiyskoy Federatsii glazami uchiteley [Problems of transition to distance learning in the Russian Federation through the eyes of teachers]. M.: NIU VShE, 2020, 32 p. https://ioe.hse.ru/mirror/pubs/ share/368265542.pdf

13. Urok angliyskogo yazyka v 10 klasse «zoom» [English lesson in grade 10 “zoom”], 2020. https://www.youtube.com/watch?v=WHCqtfdwblw\&t=673s (accessed 20.10.2021).

14. Fedunova M.N. Problemy distantsionnogo obucheniya inostrannym yazykam v usloviyakh pandemii [Problems of distance learning foreign languages in a pandemic]. Simvol nauki, 2021, no. 3, pp. 119-123.

15. Andrews R. Does e-Learning Require a New Theory of Learning? Some Initial Thoughts. Journal for Educational Research Online, 2011, vol. 3, no. 1, pp. 104-121.

16. As finnish teachers move classes online, family routines change, 2020. https://finland.fi/life-society/as-finnish-teachers-move-classes-onlinefamily-routines-change/ (accessed 20.10.2021)

17. Niemi H.M., Kousa P. A case study of students' and teachers' perceptions in a Finnish high school during the COVID pandemic. International Journal of Technology in Education and Science (IJTES), 2020, vol. 4, no. 4, pp. 352-369. https://doi.org/10.46328/ijtes.v4i4.167

18. How countries are using edtech (including online learning, radio, television, texting) to support access to remote learning during the COVID-19 pandemic. https://www.worldbank.org/en/topic/edutech/brief/how-countries-are-using-edtech-to-support-remote-learning-during-the-covid-19pandemic (accessed 20.10.2021) 
19. Loima J. Socio-Educational Policies and Covid-19 - A Case Study on Finland and Sweden in the Spring 2020. International Journal of Education and Literacy Studies, 2020, vol. 8, no. 3, pp. 59-75. http://dx.doi. org/10.7575/aiac.ijels.v.8n.3p.59

20. Paula Taipale. Finnish Primary Teacher's Experiences of Remote Teaching during COVID-19 School Closures. Master's Thesis, 62 p. January 2021. https://www.utupub.fi/bitstream/handle/10024/151160/PaulaTaipale.pdf?sequence $=1 \&$ isAllowed $=y$ (accessed 20.10.2021)

21. Riikka Aarnos. Teaching and supporting students with special-educational needs at distance during the COVID-19 school closures in Finland: Special needs teachers' experiences. Thesis for Master's degree. https://www.doria.fi/bitstream/handle/10024/180693/aarnos_riikka.pd$\mathrm{f}$ ? sequence $=4 \&$ isAllowed $=\mathrm{y}$ (accessed 20.10.2021)

22. Senni Rekola, Mona Siltanen. Finnish EFL teachers' experiences during the emergency remote teaching period in spring 2020. Master's Thesis, https:// jyx.jyu.fi/bitstream/handle/123456789/74516/URN\%3aNBN\%3afi\%3ajyu-202103081873.pdf?sequence $=1 \&$ isAllowed $=y$ (accessed 20.10.2021)

23.ZOOM. https://helpdesk.it.helsinki.fi/en/instructions/collaboration-and-publication/video-conferencing/zoom (accessed 20.10.2021)

\section{ДАННЫЕ ОБ АВТОРЕ}

Лехницкая Полина Александровна, студент

Федеральное государственное автономное образовательное учрежждение высшего образования «Казанский (Приволжский) федеральный университет»

ул. Кремлевская, 18. г. Казань, 420008, Российская Федераџия lekhnitskaya.polina@gmail.com

\section{DATA ABOUT THE AUTHOR}

\section{Polina A. Lekhnitskaya, student}

Kazan (Volga region) Federal University

18, Kremlevskaya Str., Kazan, 420008, Russian Federation

lekhnitskaya.polina@gmail.com

ORCID: 0000-0002-3689-3213 